\title{
S-43: Type and Frequency of Dietary Supplement Use by Iranian Soccer Players
}

\author{
Faezeh Maleklou, Tohid Seifbarghi \\ Sports Medicine Research Center, Neuroscience Institute, Tehran University of Medical Sciences, Tehran, \\ Iran
}

\begin{abstract}
INTRODUCTION: The aim of this study was to determine the type and frequency of dietary supplements use among elite soccer players in 2011/12 season of Iran's Premier Football League.

MATERIALS-METHODS: This was a cross-sectional study. We randomly selected 13 teams from 18 teams in 2011/2012 season. All players of each team took part in our study. A total of 234 soccer players enrolled in the study. Data were collected in seven-point times using a questionnaire.

FINDINGS: All players consumed at least one single supplement. The most common used supplements among athletes were vitamins $C$ and E. No significant association was found between position played and the type or frequency of supplements use by athletes $(p>0.05)$. There was no significant relationship between the ranks of teams at the end of season and types or frequency of dietary supplements consumed by players $(p>0.05)$.

CONCLUSION: Our findings indicate that the usage of dietary supplements among Iranian elite soccer players is prevalent. Future studies are required to reveal the beneficial and potential hazards of these supplements on athletes' physical performance and their health.
\end{abstract}

Available at: http://journalofsportsmedicine.org and http://dx.doi.org/10.5152/tjsm.2017.047

(C2017 Türkiye Spor Hekimleri Derneği. Tüm hakları saklıdır. 